\title{
Reflexiones socio-críticas en la estructura novelística de Los parientes de Ester de Luis Fayad.
}

Preparado por:

Dra. Saadeya Mousa Abd El Azeem

Profesora en El Departamento de Español

Facultad de Al-Alsun - Universidad de Kafr El Sheikh

Publicado en: Journal Of Literary Studies and Humanities, 2018.

ISSN: $2314-7431$.

Faculty of Arts - Kafr El Sheikh University,

$\underline{\text { Reflexiones socio-críticas en la estructura novelística de LoS }}$

parientes de Ester de Luis Fayad.

Preparado por: Dra. Saadeya Mousa Abd El Azeem

Profesora en El Departamento de Español

Facultad de Al-Alsun - Universidad de Kafr El Sheikh

Email: Saadeya.mousa_2011@yahoo.com

\section{Resumen:}

En efecto, la investigación sobre la nueva narrativa urbana es una rama fructífera y enriquecida para los interesados por la literatura hispanoamericana. Sin embargo, son pocas las investigaciones sobre el tratamiento crítico de dicha temática en las obras narrativas de los escritores hispanoamericanos. Por lo que, intentamos hacer reflexiones socio-críticas de este subgénero narrativo, sobre todo en Los parientes de Ester de Luis Fayad.

En primer lugar, hablamos de la trayectoria vital y literaria del escritor Luis Fayad (1944), que es uno de los eminentes escritores colombianos de descendiente árabe. También, arrojamos la luz sobre los rasgos definitorios de su narrativa sobre todo en Los parientes de Ester (1978), que es una de las novelas más reveladoras de la nueva narrativa urbana, ambientada en Bogotá. 
Entonces, partimos de un estudio crítico del contexto socio-histórico de Colombia de los años sesenta y setenta y su influencia sobre la narrativa de esta época. Así como, hablamos de la emigración y la urbanidad, que aparecen obviamente como dos fenómenos influyentes no sólo en Los parientes de Ester, sino en toda la narrativa de Luis Fayad.

En segundo lugar, este trabajo se propone discutir las reflexiones estéticas en la estructura novelística de Los parientes de Ester, partiendo de un estudio analítico de la focalización o el punto de vista narrativo, los personajes protagónicos, la dimensión espacial y temporal y el lenguaje bien utilizado en esta novela de estudio, como veremos y reconocemos a continuación.

Palabras Clave: Socio-crítico - Los parientes de Ester - Luis Fayad.

\section{Introducción}

Luis Fayad es un autor colombiano de la segunda mitad del Siglo XX. Nació en Bogotá en 1945. Estudió Sociología en La Universidad Nacional a principios de los años setenta. Es traductor, guionista, periodista y novelista. Su trabajo en el mundo del periodismo le ha llevado a vivir en diversas ciudades europeas como; París, Barcelona y Berlín, donde reside recientemente. Las primeras incorporaciones de Luis Fayad en el campo literario se dan mediante sus experiencias repetidas en la preparación de guiones para teatro, radio y televisión, es que él forma parte del grupo escénico en su infancia y su juventud, añadiendo que su madre tenía más inclinaciones literarias, contándole historias relacionadas con el pasado libanés. El propio Luis Fayad nos cuenta: «Del ambiente de mi casa, mi madre era una persona inclinada a la literatura. Además, tenía una gran imaginación para inventar cosas o para adornar cualquier cuento. [...] En el caso de mi padre, él me contó que en su juventud le

\footnotetext{
1 - Véase:- Marcos Fabián Herrera : En una entrevista de Marcos Fabián Herrera con Luis Fayad, www.comentariosdelibros.com/entrevista-luis.fayad/120e2g29a.htm - Fecha de visita de la página web : 20 /05/2018, 8 :00 PM.
} 
regaló a mi madre un libro con poemas escritos a mano por los propios poetas colombianos» ${ }^{2}$.

Luis Fayad es autor de varios novelas y cuentos, entre ellos destacan Los parientes de Ester (1978), Caída de los puntos cardinales (2000), y Testamento de un hombre de negocios (2004). Así como, ha cultivado antologías de cuentos como; Los sonidos del fuego (1968), y Una lección de la vida (1984). Entre sus relatos, destacan La carta del futuro (1993), y El regreso de los ecos (1993).

Teniendo en cuenta que, Luis Fayad es descendiente de libaneses, lo cual se ve reflejado después en su trayectoria literaria. En palabras del propio Fayad, «Ni lo uno ni lo otro; de niño convivía con ese mundo árabe. Claro, sin darme cuenta estaba escribiendo la novela que salió ahora. Y parte de mis otros libros se ve un poco la atmósfera árabe, con su idioma y con los grupos libaneses de Latinoamérica que se reúnen, bueno, sobre todo se reunían» ${ }^{3}$. Así que, Luis Fayad presenta en su narrativa la incorporación del inmigrante árabe en el tejido de la sociedad colombiana, y las dificultades afrontadas por las divergencias idiomáticas y doctrinales, que a su vez forman un estímulo y un reto para su integración en dicha sociedad latinoamericana, como es el caso de; Los parientes de Ester y La caída de los puntos cardinales, que se convierten en dos obras novelísticas brillantes en toda la literatura hispanoamericana de finales del siglo XX.

\section{I- Breve aproximación al contexto socio-histórico en la narrativa de Luis} Fayad.

En este apartado hacemos una breve aproximación a la novela colombiana en los años 70. Así como, estudiamos los rasgos esenciales de la nueva narrativa urbana, y sus reflexiones socio-críticas en Los parientes de Ester de Luis Fayad.

2 - Alejandro Lorente (2012): «La madeja desenvuelta. Conversación con Luis Fayad», Editorial: U. Javeriana, P. 115.

3 - Ibíd. P. 114. 
Luis Fayad pertenece a una generación literaria renovada, que es un grupo pionero en la nueva narrativa colombiana denominada Post Boom ${ }^{4}$ hispanoamericano. Así, el escritor colombiano comparte protagonismo con escritores de la talla de Fernando Vallejo, Plinio Apuleyo Mendoza, Héctor Collazos, y Moreno Durán.

Evidentemente, la novela colombiana en los años 60 adquiere un estatus destacable con la publicación de Cien años de soledad (1967) del eminente escritor García Márquez, que, a su vez, se convierte en un paradigma para todos los escritores de su época. De acuerdo con las palabras de Raymond Williams, «[...] en Colombia, hacia 1975, la "sombra" del macondismo comenzó a ser más sobre llevable» ${ }^{5}$.

Las creaciones narrativas de los escritores colombianos de los años $60 \mathrm{y}$ 70 se califican como modernas y postmodernas. Es una «generación de intelectuales que tuvieron en su niñez la experiencia de la violencia, la Revolución Cubana en su adolescencia y el Frente Nacional en su madurez». Ya que el Frente nacional desempeña un papel fundamental en la renovación de la intelectualidad de los ciudadanos y los conceptos de la ciudadanía, creando el denominado proceso de "Bogotazo"7.

4 - En cuanto al término Post Boom : La aparición de esta corriente comienza en los años 70 con la publicación de “Soñe que la nieve ardía” de Antonio Skármeta en 1975. El Posboom cuenta con otras denominaciones entre ellas destacan; novísima generación, infrarrealismo, hiperrealismo. Sus escritores representativos son; la chilena Isabel Allende, el colombiano Rafael Chaparra y Luis Fayad, Los mexicanos Elena Poniatowska y Fernando del Paso, etc. Véase : Javier Navarro | Sitio: Definición ABC | Fecha: enero. 2017 | URL: https://www.definicionabc.com/historia/postboom.php, Fecha de visita de la página web : 01 /07/2018, 8 :00 PM.

5 - William Raymond (1991) : Novela y poder en Colombia: 1844-1987. Trad., Álvaro Pineda-Botero. Bogotá: Tercer Mundo Editores, P. 246.

${ }^{6}$ - Ibíd. P. 254.

7 - En cuanto al término "Bogotazo": Con el frente Nacional (1958 - 1947), las fronteras políticas entre los partidos tradicionales tienden a borrarse y se consolidan los 
Curiosamente, los escritores hispanoamericanos abandonan el realismo mágico ${ }^{8}$ - característica permanente del Boom de los años 60 -, concediendo un enorme interés a las narraciones testimoniales y existenciales, y la aparición de la temática urbana y metafísica. De modo que, los autores mantienen un compromiso político con la realidad hispanoamericana. Y aquí me inspiro en las palabras de Donald L. Shaw: «Las fuerzas centrípetas de la narrativa hispanoamericana que fueron algo opacadas por el éxito del Boom estallaron en los años 70. [...], fue la narrativa testimonial que, como vimos, se sitúa en el polo opuesto del experimentalismo y del cosmopolitismo. [...], los del Posboom no han vuelto hacia un realismo ingenuo. Muy conscientes del cuestionamiento de la capacidad del escritor de reproducir la realidad mediante el uso de lenguaje directamente referencial» ${ }^{9}$. Por eso, los autores del Posboom intentan observar la realidad de la sociedad hispanoamericana e interpretar las vicisitudes de los hechos políticos y sociales de la época, orientándose hacia una problematización más aguda de los fenómenos históricos mediante el uso de paradigmas narrativos derivados de lo experimental y existencial.

La nueva narrativa urbana de los años 70 es un rasgo destacable para los escritores del Posboom, entre los que destacan José Antonio, Manuel Mejía Vallejo, umberto Valverde y Luis Fayad. Puesto que, la urbanidad se representa como una dimensión espacial expresiva de los intercambios socio-culturales e históricos latinoamericanos generalmente y colombianos especialmente. Sin embargo, el gran concepto de modernización impuesto por Hispanoamérica a mediados del Siglo XX coincide en Colombia con el fenómeno histórico «[...]

grupos guerrilleros del país, pasando la violencia de los campos a la ciudad, proceso que se inició con el "Bogotazo". [...] El Frente Nacional, como partido único, se convirtió en un régimen autoritario de las élites liberal y conservadora. (Véase : Hésper Eduardo Pérez (1989): Proceso del bipartidismo colombiano y Frente Nacional, Bogotá, Universidad Nacional de Colombia. PP. 102 - 103.

8 - Véase: Donald L. Shaw (1999) : Nueva narrativa hispanoamericana. Boom. Posboom, Posmodernismo, 6a . ed. Cátedra, S.A., Madrid. P. 339.

9 - Ibíd. P. 260. 
denominado "Bogotazo", episodio histórico de "largo alcance" que no sólo marca nuevos rumbos para el país, sino que divide la historia de la capital, la cual continua apegada a su mentalidad tradicional bajo una pomposa apariencia metropolitana» ${ }^{10}$. Y, por consiguiente, esta dualidad contradictoria generada de la tradicionalidad y la modernidad, dibuja nuevos aspectos multiculturales caracterizados por la resistencia en un intento de conseguir las libertades anhelados.

En efecto, el desarrollo de Bogotá en el Siglo XX pasa por tres fases fundamentales - según nos informa el investigador Alberto Saldarriaga - «[...] la fase formativa (1900 - 1950), la fase de crisis (1950 - 1980) y la fase de relativa estabilización (1980 - 1990)» ${ }^{11}$. Lo que nos interesa en nuestro estudio es la segunda fase - de crisis -, que es un registro incuestionable de la obra narrativa de Luis Fayad. Puesto que, en esta fase histórica de la capital colombiana acaecida entre 1950 y 1980, ocurren graves transformaciones demográficas debido a la inmigración masiva de rurales colombianos que padecen la pobreza y la ignorancia en busca de nuevas formas ilustradas de vida urbana. Además, "[...] se instalan la agresividad y los vicios en el comportamiento ciudadano diluyéndose el tradicional "sentido" bogotano, el cual es casi siempre reemplazado por expresiones de significado negativo» ${ }^{12}$.

Por lo tanto, las contraposiciones y las paradojas enraizadas en la profundidad del contexto socio-histórico de Bogotá se representan motivos estimulantes e inspirados para la aparición de las obras narrativas de Luis Fayad, en las que abundan el paisaje de la ciudad bogotana, los conflictos, la

10 - Cristo Rafael, Figueroa Sánchez (2004) : «Representaciones literarias de Bogotá (Narrativa de Luis Fayad) y de Cartagena (Narrativa de Roberto Burgos Cantor)», Universitas Humanística, núm 57, P. 100.

11 - Alberto Saldarriaga (1991) : La cultura urbana en Bogotá. Misión Bogotá, Siglo $X X I$, (junio, texto fotocopiado), p. 17.

12 - Cristo Rafael, Figueroa Sánchez (2004): « Representaciones literarias de Bogotá (Narrativa de Luis Fayad) y de Cartagena (Narrativa de Roberto Burgos Cantor)», Op. Cit., P. 110. 
desconfianza, la intolerancia, la falta de respeto, la violencia y la corrupción de la comunidad urbana. De hecho, Luis Fayad «[...] vive de niño el desajuste de Bogotá, como estudiante de la universidad Nacional participa en sus movimientos ideológicos, la mira luego desde Europa, la lee, la escucha, la describe, la narra y la construye de nuevo» ${ }^{13}$. Así que, en la ficción narrativa del escritor colombiano figuran paradigmas sociales marginados, desesperanzas y fracasos, que se consideran de otro modo meditaciones profundas del Bogotá de mediados del Siglo XX.

Evidentemente, Luis Fayad intenta dar paso a un estilo de la narrativa socio-urbana, sobre todo con los enormes cambios y las transformaciones políticas acaecidos en el tejido social de su país, influyéndose por las corrientes existentes en su propia cultura colombiana. El escritor colombiano tiene nostalgia y anhelo hacia su patria, preocupándose por el retorno a sus raíces colombianos. Y aquí me inspiro en sus propias palabras: «En absoluto, para mí el retorno está libre. Siempre que regreso a mi país se me viene a la mente un pensamiento que se repite, y es que todos los que vienen en mi ciudad, en las ciudades de mi país, son colombianos» ${ }^{14}$.

La vocación de Luis Fayad de narrativizar la etapa más controvertida y problemática del contexto urbano de Bogotá se concentra sobre todo en 1978 con la autoría de Los parientes de Ester. En efecto, esta obra creativa se cultiva en una fase de transición entre la modernidad y la postmodernidad hispanoamericana, donde el nacimiento de una nueva sociedad liberal, cuya estética narrativa se contrasta obviamente con el realismo mágico usado de antemano. Y aquí me cito en las palabras de la escritora Paula Marín «Si bien la obra de Fayad se presenta como una respuesta en el campo a la propuesta del realismo mágico garciamarquiano, su realismo conservador presenta una

\footnotetext{
13 - Ibíd. P. 101.

14 - Alejandro Lorente (2012): « La madeja desenvuelta. Conversación con Luis Fayad», Op. Cit., P. 115.
} 
visión monológica de la realidad que no permite configurar alternativas de actuación para el individuo colombiano» ${ }^{15}$.

\section{Estudio socio-crítico de Los parientes de Ester.}

Este apartado tiene como objetivo ofrecer una relectura de Los parientes de Ester a partir de un estudio socio-crítico de su contexto narrativo. Puesto que, Luis Fayad sugiere «[...] una propuesta significativa y coherente a una problemática histórico- social $»^{16}$. Él presenta su obra novelística no como una respuesta acertada a la comunidad colombiana, sino la ofrece como una crítica $y$, en cierta medida, expresión de conceptos contradictorios en el mundo, donde las influencias impuestas por la modernidad en una familia conservadora que opta por la tradicionalidad del antiguo linaje árabe, evitando tratarse con la nueva sociedad urbana.

En este sentido, hacemos un análisis de los personajes protagónicos, así como describimos el impacto de los factores de la modernidad en las tres familias bien definidas en el contexto narrativo; es decir, la familia de Callejas, Camero y Mahid.

En Los parientes de Ester, Fayad nos habla de la integración del inmigrante árabe en la sociedad adoptiva, subrayando a las diferencias existentes entre los inmigrantes y los nativos mediante los parientes de la fallecida Ester, que es de descendiente árabe. De forma que, esta novela se compone de seis series narrativas desencadenadas que permiten al lector adentrarse en los pensamientos y los diálogos de los personajes, quienes son los parientes de la difunta Ester, esposa del protagonista del relato Gregorio Camero. Así que, «[...] la novela se erige como una manifestación de desaliento

15 - Paula Marín (2007) : «Acercamiento a la novela colombiana de los setenta: aproximación sociocrítica a las novelas Los parientes de Ester de Luis Fayad y Juegos de Mentes de Carlos Perozzo». Bogotá D.C., P. 57. Disponible en:http://cienciagora.com.co/imgs2012/imagenes/TESIS_PEROZZO_FAYAD.pdf,

Fecha de visita de la página web : 20 /02/2018, 05 :00 PM.

16 - Michael Foucault (1996) : De lenguaje y literatura, Barcelona, Paidos, P. 69. 
del ser humano frente a la promesa de la modernidad, Bogotá se convierte en un referente del vaivén de las diferencias de clase, así como sus representaciones sobre lo urbano» ${ }^{17}$.

Paralelamente, Los parientes de Ester aborda la problemática de la pobreza en la que se hundió la sociedad bogotana, haciendo constantes referencias y alusiones al dinero y al estado económico miserable, es que algunas personas solicitan el dinero, otras no lo prestan, otros hacen negocios en Estados Unidos en un intento de huir de la miseria. Así que, el escritor colombiano nos presenta un panorama de hechos cotidianos, donde su voz se mueve paulatinamente entre los personajes del árbol genealógico - Familia de Ester - gregoriano. Intenta tejer los hilos de la trama mezclada con diversos sentimientos humanos en un tono humorístico e irónico, como si fuera una experiencia cinematográfica.

Los parientes de Ester relatan la historia de Gregorio Camero - pertenece a una familia tradicional -, que le faltan cinco años para estar jubilado, y Ángel Callejas - de clase media -, que ya está jubilado. Desde el inicio de los sucesos de la historia, Gregorio Camero representa la figura del desencanto y la desesperanza por la muerte de su esposa Ester, es que «alcanzó a pensar que la vida es una estafa» ${ }^{18}$. Pues, Ester es un monitor fundamental en torno al cual gira todos los hechos de la novela, aunque es el único personaje silenciado. «Desde el título, Los parientes de Ester deja al margen a Gregorio como entidad individual, pues él también resulta subsumido en la categoría general que encierra la nominación "parientes", ya que no se trata de distinguir a los individuos que conforman una familia, sino la familia como tal, enunciadora de

17 - Cristian Felipe García Spina (2017): «Cartografía simbólica en la ciudad de Bogotá a partir de la narrativa urbana en la década de los 80. Análisis de las novelas Sin remedio y Los parientes de Ester»., Universidad Santo Tomás de Bogotá, Facultad de Sociología, Bogotá D.C. 2017, P. 67.

18 - Luis Fayad ((1994), Los parientes de Ester. México D.F.: Rayuela Internacional, P. 8. 
un orden tradicional del cual el viudo de Ester no forma parte» ${ }^{19}$. Por lo que, Ester es la causa de la presencia del protagonista Gregorio Camero, aunque este último es marginado debido a su linaje vergonzoso. La protagonista Mercedes Callejas dice: "[...] Yo no sé cómo José dejó casar a Ester con Gregorio. Es un advenedizo, no tiene pasado, no se le conocen ni padres, ni hermanos, ni parientes $»^{20}$. Así que, Gregorio Camero se presenta desde el comienzo del relato como personaje excluido. Y aquí me cito en sus propias palabras después de la muerte su esposa Ester; «Nunca pensé que tuviera tantos parientes-dijo [Gregorio]. También Doris sonrió para compartir la broma.

-No son parientes suyos -dijo-, son parientes de Ester.

-Y son parientes políticos míos - explicó Gregorio Camero.

Doris volvió la cara solo para ver si el hombre hablaba en serio» ${ }^{21}$.

Los sucesos de la novela inician con la muerte de Ester, esposa del protagonista Gregorio Camero que se queda viudo a lo largo del relato y tiene tres hijos. La muerte de la esposa Ester se considera un fundamental factor y un motivo estimulante para el desarrollo de todos los sucesos, es que reconocemos los desastres de sus parientes, sus desesperanzas y sus fracasos. Así que, los protagonistas Gregorio Camero, Ángel Callejas y Amador Callejas reconocen al final del relato la maldad de la sociedad donde viven, sintiéndose la existencia de otras opciones en la vida. Ellos tienen el sentido de que sus desgracias y sus problemas propias no sean personales, sino que incluyan toda la comunidad urbana. Y, por consiguiente, el destino individual de los protagonistas se convierte en una voz colectiva.

19 - César Olivares (2018): «La modernidad y el fracaso de la familia conservadora en Los parientes de Ester de Luis Fayad», disponible en: https://cesarolivares.blogspot.com/2018/09/la-modernidad-y-el-fracaso-de-la.html, fecha de visita de la página web : 10/10/2018

20 - Luis Fayad (1994), Los parientes de Ester. Op. Cit., P. 34.

21 - Ibíd. P. 13. 
En efecto, Los parientes de Ester plantea una crítica aguda al sistema tradicional estamental con sus fundamentos feudales, plasmada en la familia Callejas, que pertenece de antemano a la clase más alta en la sociedad bogotana, pero sufre después de una crisis financiera. Pues, la familia Callejas se siente obligada a mantener su jerarquía social, denunciando la modernidad. Así, «Este tipo de modernidad es el que se denuncia en la novela al presentar a los Callejas como una familia de abolengo venida a menos, sin dinero, cuyos integrantes se estafan entre sí y en cuyo seno existe un hermano (Amador, hasta el nombre es irónico) que vive de pedir prestado dinero que nunca devolverá» ${ }^{22}$. Por lo tanto, esta familia representa un arquetipo tradicional colombiano con una perspectiva discriminadora y racista de la clase baja, que a su vez recurre a hechos inmorales para mantener su prestigio en el nuevo mundo modernizado.

Por un lado, la novela nos ofrece la carencia de algunos personajes Camero, Dorís, Rosa - de encarnar la conciencia colectiva de esta clase media, «[...], son personajes que representan el país de la convulsión, las crisis y las incertidumbres, y también de las esperanzas, la búsqueda. [...] también hay mucho de lucha frente a las incertidumbres hay decisiones ${ }^{23}$, pues mantienen la resignación a los paradigmas tradicionales, rechazando el deseo de cambio ante las nuevas transformaciones en el tejido social bogotano.

Al otro lado, en Los parientes de Ester, la clase baja surge plasmada en Dorís - la empleada doméstica de Gregorio Camero - y la otra figura - Rosa conviviente de Ángel Callejas. A pesar de la pertenencia de Rosa a la clase baja, se representa como una mujer que defiende su dignidad como un individuo en la

22 - César Olivares (2018): «La modernidad y el fracaso de la familia conservadora en Los parientes de Ester de Luis Fayad», disponible en: https://cesarolivares.blogspot.com/2018/09/la-modernidad-y-el-fracaso-de-la.html, fecha de visita de la página web : 20/09/2018, 09 :00 PM .

23 - Marcos Fabián Herrera : En una entrevista de Marcos Fabián Herrera con Luis Fayad, disponible en: $\underline{\text { www.comentariosdelibros.com/entrevista- }}$ luis.fayad/120e2g29a.htm, Op. Cit., 
sociedad, ya que no se influye por las miradas discriminadoras llenas de odio por parte de la familia de Ángel Callejas. Y aquí me inspiro en las palabras del narrador: «Mercedes miró a su hermano, examinó a la mujer y se ofendió con el brillo de igualdad que proyectaban sus ojos. Se volvió hacia Ángel y le preguntó quién le había encargado una muchacha del servicio» ${ }^{24}$. Así, Rosa es un arquetipo femenino tradicional, que su crítica a las clases más altas dominantes tienen como objetivo la búsqueda de intereses personales, es que ella tiene un comportamiento defensivo frente esta clase alta. Sin embargo, su personalidad se caracteriza por la pasividad, esperando la llegada de un hombre de la clase más alta para cambiar su vida, lo cual refleja la perspectiva comprometida y resignada de la imagen femenina de la clase baja.

Paralelamente, el escritor colombiano nos expone otras figuras jóvenes las primas Hortensia y Alicia, hija de Nomar Mahid, un hombre de negocios -, que se ven correspondidos con los intercambios modernistas de la vida urbana, viviendo al estilo estadounidense, lo cual provoca una crisis de identidad y un complejo de inferioridad para Hortensía en algunas veces, porque quiere ser otra imagen similar a la de su prima Alicia, sin ninguna confianza en sí misma, pero todos sus intentos fracasaron. Así, "[...] Hortensia le dijo a su prima que iba a trabajar durante las vacaciones. No comprendió entonces el asombro de Alicia, [...]. Hortensia recordó que estaba a punto de acceder y que lo único que la mantuvo firme fue pensar en las invitaciones que le haría a su prima [...] cuando Alicia la quisiera tanto como Hortensia a ella, le contaría que lo había hecho para que la quisiera más» ${ }^{25}$.

Amador Callejas - otro protagonista en la novela - desempeña un papel importante en el desarrollo de los sucesos. Así que, representa el fracaso de la clase tradicional frente a la modernidad. Su familia le califica como "Oveja negra". Se convierte en un estafador, que pide una parte del sueldo de su sobrina, lamentándose siempre de su situación económica cambiante. Y aquí me inspiro en sus propias

\footnotetext{
24 - Luis Fayad (1994): Los parientes de Ester. Op. Cit., P. 138.

25 - Ibíd P. 122.
} 
palabras ; «-iQué hacemos nosotros tan pobres y tan de buena familia! » ${ }^{26}$. También Amador Callejas es un arquetipo obvio de aquella clase tradicional conservadora colombiana, que no se pueda coincidirse con las nuevas transformaciones ocurridas en el tejido de la sociedad de los años 70. En un discurso entre Gregorio y Amador Callejas, este último critica la situación del gobierno, diciendo: «Quizá el gobierno podría hacer una buena obra si la gente no lo criticara tanto. Piensa en las grandes empresas que se han llevado a cabo, industrias, carreteras, piensa en los parques, en los centros de beneficencia, en los monumentos» ${ }^{27}$.

\section{Reflexiones sobre la estética narrativa en Los parientes de Ester.}

\section{El punto de vista narrativo en Los parientes de Ester.}

En este apartado, presentamos el análisis de la estética de Los parientes de Ester, aportando un enfoque disciplinar de Genette ${ }^{28}$. En Los parientes de Ester, el punto de vista narrativo - según Genette - es metadiegético, donde hay una narración diferente dentro de la narración primaria. No se mantiene una estrucura líneal y lógica en la narración de los hechos narrativos. Ya que la diversidad del punto de vista narrativo es uno de los rasgos definitorios del postboom $^{29}$.

En Los parientes de Ester, el escritor tácito aparece mediante la voz narrativa, desempeñando diversos papeles en el relato de los hechos. A veces, se comporta como testigo de los hechos de los personajes. Otras veces, se comporta como intermediario que mantiene la coherencia de la trama del discurso narrativo. «[...] en muchos casos el sincretismo entre la voz narrativa y las distintas focalizaciones genera instancias discursivas donde cobran sentido las dinámicas sociales que ocurren en el seno de la ciudad y las diferentes

\footnotetext{
26 - Ibíd. P. 39.

27 - Ibíd. P. 174.

28 - Véase: Gerard Genette (1972): Discurso del relato, Barcelona, En: Figuras III.: Lumen., Esp. Introducción, PP. 71 - 76 y “Voix“ 225- 267.

29 - Véase : Ricardo, Gutiérrez Moat (1988) : « La narrativa latinoamericana del posboom», Revista Interamericana de Bibliografía XXXVIII, PP. 3 -10.
} 
formas de habitarla, padecerla o conquistarla» ${ }^{30}$. Por eso, anotamos que la focalización se incorpora ciertamente en la problemática de la decadencia de la familia de Ester, que por fin opta por mantener sus paradigmas tradicionales.

\section{La dimensión espacial en Los parientes de Ester.}

En Los parientes de Ester, Luis Fayad narrativiza el concepto de la urbanidad mediante su descripción subjetiva de la dimensión espacial de Bogotá, como escenario fundamental de los acontecimientos de la novela.

Curiosamente, Luis Fayad intenta crear una cosmovisión subjetiva del Bogotá de los años 60 y 70, en cuanto a su dimensión espacial privada y pública, donde surgen distritos, calles, oficinas, restaurantes y bares. «[...] no es entonces el mapa urbanístico lo que identifica en la novela, sino el carácter que Fayad imprime a cada personaje y a la relación de éstos con aquélla en tanto espacio determinado y determinante» ${ }^{31}$. Así, el escritor colombiano recorre por las carreteras de la ciudad bogotana de una manera más experimental a través de sus personajes que observan el establecimiento de sus edificios y sus residentes que los habitan diariamente. De manera que, «[...] La dinámica del centro / periferia enmarca la trama del recorrido de los actantes, el mapa se despliega de sur a norte, tomando como referencia de encuentro el centro de la ciudad, como espacio caótico, donde converge la avenencia y la ilusión de Camera, pero donde también se representa la frustración y el tedio de la existencia» ${ }^{32}$. Por lo que, la imagen de la capital colombiana se perfila a través de las actitudes

30 - Cristo Rafael, Figueroa Sánchez (2004) : Representaciones literarias de Bogotá (Narrativa de Luis Fayad) y de Cartagena (Narrativa de Roberto Burgos Cantor), Op. Cit., P. 103.

31 - Alberto Guillermo Arévalo (1994): «Luis Fayad: narrador de lo contemporáneo ». La novela colombiana ante la crítica. 1975 -1990. Luz Mary Giraldo. Bogotá, Cali: Centro Editorial Javeriano y Editorial de la Facultad de Humanidades de la U. del Valle, P. 255.

32 - Cristian Felipe García Spina (2017): «Cartografía simbólica en la ciudad de Bogotá a partir de la narrativa urbana en la década de los 80. Análisis de las novelas Sin remedio y Los parientes de Ester», Op. cit., P. 67. 
y los comportamientos cotidianos de los personajes protagónicos, que padecen la mediocridad y el tedio de la vida urbana. También, él echa la luz sobre las doctrinas ideológicas de los grupos sociales, que sobreviven en la sociedad urbana influenciada por los factores del capitalismo y el mercantilismo.

Por eso, en el discurso narrativo - como hemos hablado detalladamente anotamos la presencia de diversos valores opuestos influyentes por la dimensión espacial, por ejemplo; el fraude de Amador, el deseo de Honorio de establecer una industria textil en Estados Unidos, el anhelo de Hortensía de ser otra imagen de su prima Alicia, las clases más altas - Ángel - que viven en el barrio Teusaquillo $^{33}$ con pisos brillantes y las clases bajas - Rosa - que viven en un apartamento humilde en el Barrio Santa Fé, etc.

\section{El tiempo narrativo en Los parientes de Ester.}

Luis Fayad emplea una técnica narrativa temporal - extra-textual y textual interna según Genette ${ }^{34}$ - significativa y coherente, que coincide con el hilo de la trama narrativa.

El tiempo extra-textual usado en Los parientes de Ester es de ambientación contemporánea, es que los hechos del relato suceden en los años 60 y 70 - la época contemporánea del autor -, sobre todo en una época tan grave en la historia de Colombia, es decir; durante el Frente Nacional y el proceso del "Bogotazo ", que hemos aludido antes. En este sentido, los deseos frustrados y la desintegración de la familia Callejas - los parientes de la fallecida Ester encarnan ciertamente una imagen paradigmática de la clase social degradada del Bogotá de los años 60 y principios de los años 70 . Dicha clase que se ve sumergida en una dualidad de valores y morales contradictorios.

\footnotetext{
33 - Véase: Luis Fayad (1994): Los parientes de Ester. Op. Cit.,

34 - Véase: Gerard Genette (1972): Discurso del relato, Barcelona, En: Figuras III.: Lumen., Esp. Introducción, PP. 71 - 76 y “Voix“ 225- 267.
} 
Ahora bien, el tiempo textual interno es líneal, porque Fayad nos presenta seis secuencias narrativas desencadenadas, siguiendo una serie cronológica lineal, sin retrospecciones ni anticipaciones temporales.

\section{EI lenguaje en Los parientes de Ester.}

Luis Fayad cuenta los hechos de Los parientes de Ester en un lenguaje sencillo y cotidiano mezclado con una crítica aguda, narrando la cotidianidad de una familia bogotana de la clase media.

El escritor colombiano retrata los claroscuros de la sociedad bogotana, mediante el uso de un lenguaje realista estricto y conciso. Por eso, se enmarca dentro del «Realismo neo-crítico, que es una mirada que pretende explorar la realidad de la vida y la realidad de la ficción dentro de una pluralidad de espacios ideológicos, sociales, estéticos, lúdicos y simbólicos» ${ }^{35}$. Fayad nos ofrece un monitor de personajes con todas sus vicisitudes en una época tan grave para todas las masas de la población colombiana, sobre todo los intelectuales, pues se configura como un desastre colectivo, ya que el Frente Nacional no plantea soluciones cruciales para los problemas de la sociedad.

\section{Conclusión}

Luis Fayad es un escritor colombiano de descendiente libanés. Se considera una de las brillantes figuras en la narrativa colombiana de la segunda mitad del siglo XX. Pertenece a una generación literaria renovada denominada el Post Boom hispanoamericano, compartiendo protagonismo con eminentes escritores como Fernando Vallejo, Héctor Collazos y Moreno Durán. Puesto que, los autores hispanoamericanos de los años 70 conceden un enorme interés a las obras creativas testimoniales y existenciales, abandonando la técnica del Realismo mágico, dándose prioridad a las narraciones testimoniales y existenciales, y la aparición de la temática urbana y metafísica.

Efectivamente, las contraposiciones y las paradojas enraizadas en la profundidad del contexto socio-histórico de Bogotá se representan motivos

35 - Fernando Ayala Poveda (1984): Manual de literatura colombiana. Educar editores. Bogotá, P. 352. 
estimulantes e inspirados para la aparición de las obras narrativas de Luis Fayad, en las que abundan el paisaje de la ciudad bogotana, los conflictos, la desconfianza, la intolerancia, la falta de respeto, la violencia y la corrupción de la comunidad urbana.

La vocación de Luis Fayad de narrativizar la etapa más controvertida y problemática del contexto urbano de Bogotá se concentra sobre todo en 1978 con la autoría de Los parientes de Ester. Por lo que, hacemos una relectura de Los parientes de Ester a partir un estudio socio-crítico de su contexto narrativo, partiendo de un análisis de los personajes protagónicos, la focalización o el punto de vista narrativo, la dimensión temporal y espacial, y el lenguaje.

Curiosamente, Los parientes de Ester plantea una crítica aguda al sistema tradicional estamental con sus fundamentos feudales. De modo que, el escritor colombiano problematiza valores que son configurados de modo perceptible en las actuaciones de sus personajes protagónicos, en sus elecciones y decisiones, configurando una manera singular de interpretar la realidad de la sociedad bogotana.

Luis Fayad narrativiza el concepto de la urbanidad mediante su descripción subjetiva de la dimensión espacial de Bogotá. De hecho, el retrato de la capital colombiana se perfila por medio de los comportamientos cotidianos de las figuras protagónicas, cuyas trayectorias vitales están repletas de dificultades y obstáculos de la vida urbana, echando la luz sobre las doctrinas ideológicas de los grupos sociales, que sobreviven en la sociedad urbana influenciada por los factores del capitalismo y el mercantilismo.

Paralelamente, en Los parientes de Ester, Luis Fayad narrativiza el concepto de la urbanidad mediante su descripción subjetiva de la dimensión espacial de Bogotá, como escenario fundamental de los desplazamientos de los personajes protagónicos en una época tan grave en la historia de Colombia, sobre todo con el desarrollo del fenómeno denominado "El Bogotazo ". 
Además, él retrata los claroscuros de la sociedad bogotana, mediante el uso de un lenguaje realista estricto y conciso.

Por otra parte, la focalización o el punto de vista narrativo es metadiegético, y se caracteriza por su diversidad. También, el escritor tácito aparece mediante la voz narrativa, desempeñando diversos papeles en el relato de los hechos. Mientras tanto, el narrador se desliza ciertamente en el interior del tejido de la sociedad bogotana por medio de la familia de los parientes de la fallecida Ester.

Por último, Luis Fayad propone en su obra novelística una sugerencia significativa, expresiva y coherente, proyectando una réplica definitiva hacia la problemática de una buena parte de las masas de la población colombiana, sobre todo los intelectuales, que en este contexto forma parte crucial de una conciencia nacional colectiva, cuya impronta es percibida mediante la estructura novelística de la novela estudiada.

\section{Bibliografía.}

- Arévalo Guillermo Alberto. 1994. «Luis Fayad: narrador de lo contemporáneo». La novela colombiana ante la crítica. 1975 -1990. Luz Mary Giraldo. Bogotá, Cali: Centro Editorial, Javeriano y Editorial de la Facultad de Humanidades de la U. del Valle.

- Ayala Poveda, Fernando. Manual de literatura colombiana. Educar editores. Bogotá, 1984.

- Figueroa Sánchez, Cristo Rafael. (2004 ) : «Representaciones literarias de Bogotá (Narrativa de Luis Fayad) y de Cartagena (Narrativa de Roberto Burgos Cantor)», Universitas Humanística, núm 57, pp. 97 - 115.

- Foucault, Michael. (1996) : De lenguaje y literatura, Barcelona, Paidos.

- García Spina, Cristian Felipe. (2017): «Cartografía simbólica en la ciudad de Bogotá a partir de la narrativa urbana en la década de los 80. Análisis de las novelas Sin remedio y Los parientes de Ester.», Universidad Santo Tomás de Bogotá, Facultad de Sociología, Bogotá D.C.

- Genette, Gerard. (1972): Discurso del relato, Barcelona, En: Figuras III.: Lumen., Esp. Introducción, PP. 71 - 76 y "Voix" 225- 267. 
- Gutiérrez Moat, Ricardo. (1988) : «La narrativa latinoamericana del postboom, Revista Interamericana de Bibliografía XXXVIII», PP. 3 -10.

- Lorente Alejandro, (2012): «La madeja desenvuelta. Conversación con Luis Fayad», Editorial: U. Javeriana, PP. 113 - 117.

- Marín, Paula (2007): «Acercamiento a la novela colombiana de los setenta: aproximación sociocrítica a las novelas Los parientes de Ester de Luis Fayad y Juegos de Mentes de Carlos Perozzo». Bogotá D.C., 233 pp. Disponible en:http://cienciagora.com.co/imgs2012/imagenes/TESIS_PEROZZO_FAYAD.p $\underline{d f}$

- Pérez, Hésper Eduardo. (1989): Proceso del bipartidismo colombiano y Frente Nacional, Bogotá, Universidad Nacional de Colombia.

- Raymond, William. (1991) : Novela y poder en Colombia: 1844-1987. Trad., Álvaro Pineda-Botero. Bogotá: Tercer Mundo Editores,

- Saldarriaga, Alberto. (1991) : «La cultura urbana en Bogotá ». Misión Bogotá, Siglo XXI, (junio, texto fotocopiado).

- Shaw, Donald L. (1999) : Nueva narrativa hispanoamericana. Boom.

Posboom, Posmodernismo., 6 ${ }^{\text {a }}$ ed. Cátedra, S.A., Madrid.

\section{- Webiografía.}

- Fabián Herrera, Marcos. : En una entrevista de Marcos Fabián Herrera con Luis Fayad, www.comentariosdelibros.com/entrevista-luis.fayad/120e2g29a.htm , Fecha de visita de la página web : 20/05/2018, 8 :00 PM.

- Navarro, Javier. | Sitio: Definición ABC | Fecha: enero. 2017 | URL: https://www.definicionabc.com/historia/post-boom.php, Fecha de visita de la página web : 01 /07/2018, 8 :00 PM.

- Olivares, César. (2018): La modernidad y el fracaso de la familia conservadora en Los parientes de Ester de Luis Fayad, disponible en: https://cesarolivares.blogspot.com/2018/09/la-modernidad-y-el-fracaso-de-la.html, fecha de visita de la página web : 20/09/2018 